\title{
The Dissolution of Linguistics and the Rise of Language with Reference to Pragmatics: A Deconstructive Approach
}

\author{
Rauf Kareem Mahmood \\ Department of English, College of Languages, University of Sulaimani, Sulaymaniyah, Kurdistan Region, Iraq \\ Department of English, College of Languages, University of Human Development, Sulaymaniyah, Kurdistan Region, Iraq
}

\begin{abstract}
This paper presents a deconstructive approach to the current status of linguistics as the primary science that studies levels of linguistic analysis. The research hypothesizes that the term 'linguistics' cannot be expected to remain as an independent and robust concept. It is subject to dissolution under the main interdisciplinary outreach of the essential branches of linguistics: phonetics, phonology, morphology, syntax, semantics and pragmatics. The current paper, however, focuses on Pragmatics as a branch of linguistics. The research also hypothesizes that the relation of pragmatics to sociology and culture is stronger than the relationship between pragmatics and semantics. The main aim of the paper is to update the study of language in a way that goes beyond the closed domain of linguistics. Throughout the discussions and analyses of pragmatics between language and linguistics, it has been concluded that the study of language is in a persistent rise, whereas the domains of linguistics proper has condensed to limited fields.
\end{abstract}

Index Terms - interdisciplinary, language, linguistics, pragmatics, deconstructive approach.

\section{INTRODUCTION}

Revisiting 'linguistics' as a scientific concept requires a thorough account of the outbreak of the term, as well as an updated analysis of the founders of that branch of humanities, focusing on every component by itself. The paper approaches this issue in three steps. First, it provides a diachronic elaboration of linguistic studies. Secondly, it conducts a synchronic analysis of the current position of 'pragmatics' as the youngest major level of linguistic analysis. The third step discusses the researcher's hypothesis, and the possibility of relocating pragmatics and other primary levels of linguistic analysis in the map of language studies, as the result of deconstructing 'linguistics'.

\section{A. Historical Development of 'Linguistics'}

Studies involving discourse go back to ancient times. Plato, for example, approached language through philosophical concepts. To him, language and philosophy contributed to the establishment of 'rhetoric' as 'the art of enchanting the soul,' i.e., the technique of winning the soul by discourse.

Additionally, to Plato, grammar was a very significant tool in shaping discourse. He is the one who first classified words into parts of speech, but with different implications.

Following Plato, Aristotle considered grammar as a critical tool of studying a language. He literally priorities the separation of language and philosophy, and made a more languageoriented classification of parts of speech. To Aristotle, the term 'grammar' could be a more comprehensive concept for language studies. Before the mid-eighteenth century, language studies were limited to Greek and Latin. With Sir William Jones' attempt to relate Sanskrit to Latin, Greek, and German, European languages were compared to Greek and Latin, and later among themselves. This was called 'comparative philology'.

\section{B. The Outbreak of 'Linguistics.'}

As a term, it first appeared in the early nineteenth century. It was diachronic, i.e., analyzing the historical development of linguistic phenomena, such as language changes and the study of meaning. Among the pioneers who used the term 'linguistics' was Edward Sapir (1921). He mentioned terms such as 'linguistic structure, linguistic drift, linguistic stocks, etc.' Linguistic studies further developed and embraced several approaches to language. The most outstanding ones were functionalism, structuralism, generativism, and cognitivism.

\section{Levels of Linguistic Analysis}

Earlier linguistic studies approached language at the three primary levels of sound, grammar, and meaning. Studying sounds covered both phonetics and phonology. The internal

Journal of University of Human Development

Volume 5 No. 3(2019); DOI: 10.21928/juhd.v5n3y2019.pp1-5

Regular research paper: Published 4 July 2019

Corresponding author's e-mail: rauf.mahmood@uhd.edu.iq

Copyright (C) 2019 Rauf Kareem Mahmood. This is an open access article distributed under the Creative Commons Attribution License

(CC BY-NC-ND 4.0) 
structure of words, word order of phrases, clauses, and sentences were the main concerns of grammar, namely morphology and syntax. Meaning, however, have been a controversial area, though confined to the dictionary and contextual meanings, the former studies meaning within the domain of 'semantics,' while the latter was the main target of 'pragmatics.'

\section{INTERDISCIPLINARY STUDIES}

The term 'interdisciplinary' refers to the combination of more than one field of research. If linguistics is the scientific study of language, and language is the most influential means of communication, and communication is the backbone of all developments in almost sectors, interdisciplinary areas of research have to be considered indispensable. Interdisciplinary studies may connect language to many other natural sciences and humanities, including physics, biology, computer science, sociology, psychology, neurology, physiology and philosophy. The strong ties that link the articulation of speech sound studied under phonetics could also be firmly connected to physiology and biology. The transmission of speech sounds is in the form of sound waves, one of the significant tools of research in physics. Nonetheless, the perception of speech sounds from the ears of the speaker to the brain of the hearer is a significant task in neurology and psychology. Phonetics, alone, could be so tightly connected to several branches of natural sciences.

Interdisciplinary studies have dominated the traditional approach to linguistics. Studies that are confined to detailed analysis of single linguistic concepts are not highly preferred. Drawing the corpus data of a language's sentence structure was significant to strengthen Chomsky's generative approach to language. Currently, such studies are of great significance due to the decisive role they play in programming a robot or a smart application. Even if the traditional classification of levels of linguistic analysis is considered authentic, they are only six, namely phonetics, phonology, morphology, syntax, semantics, and pragmatics. However, interdisciplinary studies that partly contain language include anthropological linguistics, applied linguistics, computational linguistics, discourse analysis, forensic linguistics, historical linguistics, language acquisition, language documentation, lexicography, stylistics, neurolinguistics, philosophy of language, psycholinguistics, sociolinguistics, text/corpus linguistics, translation, typology and writing systems. To carry out those interdisciplinary studies, one or more of the six main branches of linguistics are required, which are themselves, as mentioned earlier, linked to other humanities or natural sciences. All these proved facts reduce the domination of linguistics and highlight the inevitable role of language. A detailed study of this case could be achieved in a profound thesis. The focus here is on the empowerment of pragmatics as an interdisciplinary field of research and its gradual disappearance as a significant level of linguistic analysis.

\section{PRAGMATICS}

Linguists and pragma-linguists have diversely defined pragmatics. Morris (1938: 30) suggests the first definition for 'pragmatics' as 'the science of the relation of signs to their interpreters.' This was part of his theory of signs organized under the term 'semiotics' which contained three major fields of analysis, viz. syntax, semantics, and pragmatics. Decades later, Levinson (1983: 5) defined pragmatics as 'the study of language usage.' Aitchison (1992: 93) provides two senses to the definition of pragmatics: a narrow sense and a broad one. The narrow sense deals with the listener's ability to arrive at the intended meaning of speakers, whereas the broad sense deals with the general principle human beings follow when they communicate. For this sense, she refers to the non-linguistic definition of pragmatics as 'the waste-paper basket of semantics.' Yule (1996: 127), on the other hand, points out that 'pragmatics is the study of intended speaker meaning.' To Finch (1998: 160), pragmatics is concerned with utterance meaning. Hudson (2000: 312), however, refers to pragmatics as 'the relation between language and its context of use, and the study of this relation.' He adds the role of analyzing the kind of relationship that could be profoundly detected between language and context. Allan et al. (2010: 67) provide a moredeveloped and relatively detailed definition of pragmatics to be 'the context-dependent assignment of meaning to language expressions used in acts of speaking and writing.' With this relatively updated version of the definition, they emphasize the role of pragmatics in both speaking and writing. All the definitions focus on the power of context to implicate and infer meanings from utterances.

\section{Definition AND DOMAIN OF CONTEXT}

No consistent definition has been detected by the researcher on the definition of context. The reason may go back to the territory of context, and its role in shaping the conversational meaning of an utterance. Ungerer and Schmid (2006: 47) consider context 'an elusive notion' due to the complexities in grasping it, while it is the backbone of pragmatics. Archer et al. (2012: 7) point out further complications about the domain of context. He states that there is little consensus about the features required in describing the production and interpretation of utterances. Ungerer and Schmid $(2006,47)$ attempt to define 'context' as 'a mental process,' inspired by Langacker's (1987: 147) definition of 'central notion of domain' to be considered 'as a context for the characterization of a semantic unit.' Allan et al. (2010: 69) postulate that 'context denotes any or all of four things:

- the world and time spoken of

- the co-text, i.e., the text that precedes and succeeds a given language expression

- the situation of utterance, and

- the situation of interpretation.'

Even if it is difficult to provide a clear-cut definition for 'context,' it is, at least, obvious that the components of context 
cannot completely surrender to bare linguistic interpretations. If pragmatics' main focus is on the making of meaning in context, that process requires several components, prominently including time, place, people, environment and utterance structure. Hence, 'context' will be more comprehensive than both 'situation' and 'setting,' and may include them partially or wholly. Resultantly, context is a more challenging concept than something which could be accounted merely for within bare linguistic phenomenon.

\section{BOUNDARIES OF PRAGMATIC CONCEPTS}

The more expanded language-based understanding and the weakened linguistic-based definition of 'pragmatics' are not only highlighted due to the multi-dimensional reference of 'context.' Revisiting major pragmatic concepts and their boundaries may yield similar outputs. Analyzing speech act theory, implicature, inference formation, face management, presupposition and deictic expressions all depend on criteria that go beyond mere linguistic measurement. The paper focuses on four essential pragmatic components, namely speech act, implicature and inference, deixis, and politeness principle.

\section{A. Speech Act}

As Thomas (1995: 51) finds out, in relatively updated interpretations, 'speech act' may also mean 'illocutionary act,' 'illocutionary force,' 'pragmatic force' or only 'force.' None of those equivalents might be studied without reference to nonlinguistic notions and tools. Speaker's knowledge of the world and experience with the speaker supersede the structural component of the utterance. What pushes a speaker to produce an utterance in a given context, i.e., the speech event, is more significant than the structural components of that utterance. Consider the alternatives in (1).

(1)

A. 'Teacher! Would you please stop talking as I got bored?'

B. Excuse me, teacher! Would it be possible to take a break?!

C. Excuse me, teacher! May I go outside for some urgency?

If a student, for example, gets bored by a class, he has to search for the best strategy to express his reaction rather than merely saying $\mathrm{A}$. If he senses that everyone else has got bored too, he may probably choose a somewhat indirect way as in B. If the matter is related to him individually, he may resort to C. Indirect ways tend to save the teacher's face from any threats. This, however, should not mean that following the strategy of being 'indirect' would meet with politeness. In a particular situation, a direct speech act could be less offensive than an indirect one. Consider (2).

(2)

A. Do not talk and focus on the class, please.

B. I don't like the gossipers in my class.

Although B is an indirect speech act produced by the teacher to end up the noise in the class, the students might be offended, and could probably react to the teacher's utterance. Being direct, as in A, would be politer and more appropriate than such indirect strategies. Hence, indirectness should not be only associated with politeness, and vice versa. Therefore, the making of the meaning of a speech act, whether direct or indirect, is a plain interdisciplinary fact that requires the involvement of various non-linguistic foundations, along with limited linguistic components.

\section{B. Conversational Implicature and Inference Formation}

In a conversation or writing, the components of the utterance might not go beyond a limited number of words and expressions ordered together to originate a grammatically well-formed structure. Here the job of grammar is suspended, and the role of implicatures and inferences start to decide the felicity or failure of the communication. What is said or written occupies a short space in communication. What the speaker implicates and how the hearer understands matter the most. This may, but not necessarily, require the involvement of other linguistic layers. Example (3) shows a conversation between Peter and Julie who meet for the first time.

(3)

Peter: What is your name?

Julie: Julie.

Peter: Yes? (said in rising pitch)

Julie: Julie.

Peter: Oh, nice to meet you, Julie. I am Peter.

A simple scan for the meaning of the word 'yes' in outstanding dictionaries would come out with the meaning 'affirmative response' to a question. 'Yes' in dictionaries never means 'please repeat.' A more deviated meaning of 'yes' could be projected in (4).

(4)

Husband: Do you believe me?

Wife (in a skeptic tone): Yes!

Husband: I knew it. You don't believe me.

Wife: But your conducts have made me lose trust in you.

Inspired by the wife's skeptic tone and the husband's follow-up statement, 'yes' in this conversation means 'no,' whereas no dictionaries annex the meaning of 'no' to 'yes,' except as mutually exclusive, i.e., the use of one excludes the use of the other. Conversational meanings added to the lexical meaning of utterances is pragmatics' major focus to reach a premium version of communication manifested by the perfect match between speaker's implicature and hearer's inference, named 'imference' (Mahmood 2015). Reaching an imference requires the contribution of other fields, prominently including psychology and sociology. The semantic analysis of the meaning, however, is only necessary to check the rate of deviation of the produced utterance from the conventional sense within sentential and/or lexical semantic points of view. 


\section{Deictic Expressions}

Archer et al. (2012: 26) refer to Lyons (1977: 37) and Levinson (1983: 54)'s postulations on deictic expressions. They find out that deixis encodes or grammaticalizes the characteristics of a speech event, including the status of participants, the nature of activities or states addressed in the utterance, and the spatiotemporal context.

Unveiling the conversational meaning of an utterance that contains deictic expressions requires a clear relationship between that expression and the exact situation. In example (5), some of the terms have their semantic denotation, but they need contextual non-linguistic analysis to reach the precise purpose behind the use of each deictic expression.

\section{(5)}

A. I want you to answer this question.

B. Doctor James arrived here yesterday.

In $\mathrm{A}$, both the speaker and the hearer are unidentified individuals, unless we know who both 'I' and 'you' refer to in the actual context of the speech event. The demonstrative 'this' specifies a given question, probably among others. Hence, in the context of the situation, some pointing by the speaker to the intended question should be made either verbally or nonverbally. As for B, however, the least problematic part could be the identification of deictic expression 'doctor,' since it specifies 'James' who is the doctor, among other people holding the same name, or may focus on 'doctor James' among other doctors. However, the meaning of 'here' as a place or spatial deixis and 'yesterday' as a time or temporal deixis requires genuine knowledge on the exact place and time. To do so, both the speaker and the hearer need to know the exact location 'here' refers to and the exact date 'yesterday' specifies.

This process could be partly associated with semantics. Hence, as Chapman (2011: 40) points out, deixis could be located at the borderline between semantics and pragmatics. This indispensable need for contextual non-linguistic infrastructures to understand the actual meaning of deixis applies to all types of deictic expressions, which have been classified by Archer et al. (2012: 26) into six types: personal deixis, social deixis, place/spatial deixis, emphatic deixis, time/temporal deixis and discoursal deixis.

\section{Politeness principle}

Chapman (2011: 133) finds out that 'politeness' describes behavior and conduct that shows respect and consideration to the hearer while preserving self-esteem to the speaker. Politeness in pragmatics is more than a mere requirement in conversation, but rather a detailed account of politeness theory that analyzes the appropriateness of meanings in social contexts (ibid). To Grundy (2000: 145f), politeness may be seen as a manifestation of etiquette and appropriate behavior.

To decide whether politeness has been observed or breached in a conversation, interlocutors depend on several criteria. The context of the situation, background knowledge, position, educational background, sex, religion, and personality of the interlocutors are among the non-linguistic criteria for judging politeness. The content of the utterance, however, could be both linguistically and non-linguistically analyzed. The same utterance could be very polite in a context and impolite in another as explained in example (6) below.

(6)

Robert to Michael: Hey Mike, you are late.

Let's suppose that Robert and Michael are close friends, but it happens that Michael has become a teacher at the same school and the same group where Robert takes extra courses. If Michael arrives late to class, it is not polite for Robert to first address him with his first name 'Mike,' and threaten his face with the statement 'You are late.' The same utterance among the same two people in a café or a party is quite reasonable and appropriate. Deciding over the politeness about (6) is not settled by linguistic principles, but rather some social norms and psychological bases.

\section{LINGUISTICS AND THE DECONSTRUCTIVE VIEW}

By now, the discussions in the previous sections must have strengthened the status of pragmatics as a science broader and more inclusive than being confined to 'linguistics,' but rather language studies. As Chapman (2011: 10) postulates, "Pragmatics should be described as outside of and separate from the mainstream of 'core' linguistics." Mahmood (2016: 129) thinks that pragmatics has received a semi-distinct path in approaching the study of meaning, from that of 'core' linguistics. Not only pragmatics but also significant areas of language studies focus on the connection between language and effective felicitous communication, rather than the traditional accounts of mere detailed linguistic inputs and outputs, i.e., focusing on the linguistic relationship among sounds, structures, and meanings.

'Deconstructive Approach/Theory' founded by Jacques Derrida, basically focuses on literary genre, in opposite to 'structuralism' and 'formalism' in literature. The term, however, could be used to identify the interpretation strategies of an utterance based on non-linguistic implications, such as sociological, political and psychological factors. Language studies have bypassed all the traditional borderlines. As referred to in Section II, accounting for language components have become indispensable in various areas, outside the scope of linguistics. Therefore, the researcher thinks that, in a few decades from now, a new term may replace linguistics that will be more inclusive of language studies.

\section{CONCLUSIONS}

Throughout the paper, the researcher has concluded that 'linguistics' in its current sense could be considered an outdated term and requires replacement by a more comprehensive scientific terminology embracing the study of language, in connection with various fields and subfields of multidimensional communication. The researcher also thinks 
that revisiting other branches of 'core' linguistics, mainly 'phonetics' and 'syntax,' may result in stronger belief in the weakening role of 'linguistics,' and the power of language studies at large. Resultantly, 'linguistics' could face deconstruction as the result of the collapse of the non-organic relationship among phonetics, phonology, morphology, syntax, semantics, and pragmatics, as well as their reunification with a broader account of human language and communication. As for pragmatics, it has been relocated by the researcher as a field of language study wider than the limited domains of linguistics. In order to find out a robust alternative term for 'linguistics', the researcher recommends the establishment of a global group of language, culture and communication researchers who can meet in person and/or visually to discuss the formation of a new terminology to replace 'linguistics', and can account for the comprehensive nature of language studies in their current status.

\section{REFERENCES}

Aitchison, J. (1992). Linguistics. London: Hodder \& Stoughton.

Allan, K., Bradshaw, J., Finch, G., Burridge, K. \& Heydon, G. (2010). The English Language and Linguistics Companion. London: Palgrave Macmillan.

Archer, D., Aijmer K. \& Wichmann A. (2012). Pragmatics: An Advanced Resource Book for Students. New York: Routledge.

Chapman, S. (2011). Pragmatics. London: Palgrave Macmillan.

Finch, G. (1998). How to Study Linguistics. London: Macmillan.

Grundy, P. (2002). Doing Pragmatics (2nd Ed.). New York: Oxford University Press.

Hudson, G. (2000). Essential Introductory Linguistics. Massachusetts: Blackwell Publishing.

Langacker, Ronald W. (2008). Cognitive Grammar: An Introduction. Ney York: Oxford University Press.

Levinson, Stephen C. (1983). Pragmatics. Cambridge: Cambridge University Press.

Lyons, J. (1995). Linguistic Semantic: An Introduction. Cambridge: Cambridge University Press.

Mahmood, Rauf K. (2016, August). "Pragmatics between Microlinguistic and Macrolinguistic Levels of Analysis" Global Journal of Foreign Language Teaching. Vol. 6, issue 3, 127-130. Retrieved from https://www.sproc.org/ojs/ https://doi.org/10.18844/gjflt.v6i3

Mahmood, Rauf K. (2015, September). “A Pragmatic Analysis of Imference as a Collective Term for Implicature and Inference" International Journal on Studies in English Language and Literature (IJSELL), Vol. 3, Issue 9, 6771. Retrieved from https://www.arcjournals.org

Mey, Jacob L. (2001). Pragmatics: An Introduction (2nd Ed.). Massachusetts: Blackwell Publishing.

Morris, C. (1938). Foundations of the Theory of Signs. In Carnap, R., Frank Ph., Joergensen J., Morris Ch., Neurath O. \& Rougier L. (Eds), International Encyclopedia of United Science (Vol. 1, No. 2). Chicago: The University of Chicago Press.

Thomas, J. (1995). Meaning in Interaction: An Introduction to Pragmatics. New York: Routledge.

Ungerer, F. \& Schmid, H. (2006). An Introduction to Cognitive Linguistics (2nd Ed.). Edinburgh: Pearson Education.

Yule, George. (1996). The Study of Language (2nd Ed.). Cambridge: Cambridge University Press. 